\title{
REDUÇÃO DE HASTE VERDE E RETENÇÃO FOLIAR NA SOJA EM RAZÃO DE MAIOR DISPONIBILIDADE DE NITROGÊNIO PELO TRATAMENTO DE SEMENTES ${ }^{(1)}$
}

\author{
Fernando Fávero ${ }^{(2)} \&$ Maria do Carmo Lana ${ }^{(3)}$
}

\begin{abstract}
RESUMO
Problemas relacionados à retenção foliar e maturação desuniforme na cultura da soja têm sido relatados em várias regiões do país, inclusive no Estado do Paraná, desafiando pesquisadores brasileiros. Várias hipóteses já foram levantadas sobre o desequilíbrio nutricional das plantas e intensificação do problema, porém nenhuma com conclusão definitiva. Com o objetivo de avaliar como a disponibilidade de $\mathrm{N}$ via inoculação e uso de Co e Mo no tratamento de sementes, associado ao uso de fungicida e inseticida, pode minimizar a retenção foliar e haste verde, instalou-se um ensaio no campo da Estação Experimental da Copacol, em Cafelândia, PR. Oito combinações de produtos foram usadas no tratamento de sementes de soja, considerando a presença ou ausência de Co e Mo, inoculante e inseticida/fungicida. Avaliaram-se o teor de $\mathrm{N}$ foliar, a frequência de plantas anormais por ocasião da colheita, a porcentagem de vagens, com $0,1,2,3$ e 4 grãos formados, o peso de 1000 grãos, o teor de umidade, a impureza na colheita e o rendimento de grãos. $\mathrm{O}$ uso do Co e Mo e a inoculação de sementes promoveram aumento do teor de $\mathrm{N}$ foliar na soja e reduziram o número de plantas anormais, refletindo positivamente no rendimento e seus componentes. Os resultados evidenciaram efeito positivo da melhor nutrição das plantas de soja com relação ao $\mathrm{N}$ na redução de haste verde e reafirmaram a necessidade do uso do Co e Mo e da inoculação de sementes.
\end{abstract}

Termos de indexação: cobalto, inoculação de sementes, molibdênio, soja louca II.

(1) Parte da Dissertação de Mestrado do primeiro autor apresentada à Universidade Estadual do Oeste do Paraná - UNIOESTE. Recebido para publicação em 8 de agosto de 2012 e aprovado em 3 de junho de 2014 .

(2) Supervisor de Pesquisa Agrícola da Cooperativa Agroindustrial Consolata (Copacol). Rua Desembargador Munhoz de Mello, 176. CEP 85415-000 Cafelândia (PR). E-mail: favero@copacol.com.br

(3) Professora Associada, Centro de Ciências Agrárias, UNIOESTE. Rua Pernambuco, 1777. CEP 85960-000 Marechal Cândido Rondon (PR). Bolsista do CNPq. E-mail: maria.lana@unioeste.br 


\title{
SUMMARY: REDUCTION OF GREEN STEM AND LEAF RETENTION IN SOYBEAN THROUGH GREATER NITROGEN AVAILABILITY FROM SEED TREATMENT
}

\begin{abstract}
Problems related to leaf retention and lack of uniformity in maturation in the soybean crop have been reported in various regions of Brazil, including the State of Parana, presenting a challenge to Brazilian researchers. Several hypotheses for this problem have been raised in regard to plants nutritional imbalance and intensification of the problem, but no definitive conclusion has been reached. A field experiment was carried out at the Copacol Experimental Farm in Cafelandia, PR, to evaluate how nitrogen availability via inoculation and the use of Co and Mo in seed treatment associated with fungicide and insecticide in soybean can minimize leaf retention and the green stem syndrome. Eight combinations of products were used in the treatment of soybean seed, considering the presence or absence of Co and Mo, inoculant and insecticide/fungicide. Leaf $N$ content, the frequency of abnormal plants at the time of harvest, the proportion of pods with 0,1,2, 3 and 4 formed seeds, 1,000 seed weight, moisture content, impurity at harvest, and grain yield were evaluated. The use of $\mathrm{Co}$, Mo and seed inoculation promotes an increase in leaf $N$ in the soybean and reduces the number of abnormal plants, with a positive reflection on soybean yield components. The results showed the positive effect of better $N$ nutrition of soybean on reduction of green stem syndrome and reaffirmed the need for the use of Co, Mo and seed inoculation.
\end{abstract}

Index terms: crazy soybean II, seed inoculation, molybdenum, cobalt.

\section{INTRODUÇÃO}

Problemas relacionados à retenção foliar e maturação desuniforme na cultura da soja têm sido relatados em várias regiões do país, desafiando pesquisadores brasileiros. A retenção foliar em soja, Glycine $\max (\mathrm{L}$.) Merril, pode ser atribuída a vários fatores, que interferem diretamente na relação fonte e dreno da planta, associados à ausência de vagens e grãos na planta. Alguns distúrbios fisiológicos interferem na formação ou no enchimento dos grãos; entre esses, podem estar os danos por percevejos, o estresse hídrico (falta ou excesso) e o desequilíbrio nutricional das plantas (Embrapa, 2008).

A principal causa conhecida de abortamento de vagens e que ocasiona retenção foliar é a presença de percevejos. Sosa-Gomez \& Moscardi (1995), estudando espécies de percevejos, concluíram que o percevejopequeno (Piezodorus guildinii) possui maior capacidade de induzir retenção foliar do que o percevejo-marrom (Euschistus heros) e percevejo-verde (Nezara viridula).

Algumas causas de desordens nutricionais foram observadas em lavouras e experimentos, associadas com baixos níveis de $\mathrm{K}$ no solo e, ou, valores acima de 50 da relação $(\mathrm{Ca}+\mathrm{Mg}) / \mathrm{K}$. Nessas condições, pode ocorrer baixo "pegamento" de vagens, vagens vazias e formação de frutos partenocárpicos (Mascarenhas et al., 2003). Recomendações técnicas que melhoram o equilíbrio nutricional e promovam melhor aprofundamento do sistema radicular das plantas, além do manejo de pragas, são indicadas para evitar distúrbios fisiológicos na soja (Embrapa, 2008).

Desde a safra de 2006, vêm sendo relatados problemas com maturação desuniforme na cultura da soja em diferentes regiões produtoras de soja do cerrado brasileiro. Essa anomalia é popularmente chamada de "soja louca II" e tem causado grandes perdas na cultura da soja, em razão da redução do rendimento e do aumento de impureza e umidade na colheita (Sá, 2012). Várias hipóteses foram sugeridas para a causa desse problema, porém nada foi confirmado. A esse respeito, na $31^{\text {a }}$ Reunião de Pesquisa de Soja da Região Central do Brasil, em Brasília, DF, foi destacada a importância de intensificar os estudos nessa área pelos pesquisadores brasileiros (Embrapa, 2011).

Na safra 2009/10, o Paraná também foi alvo dessa adversidade, que estava restrita às regiões norte $\mathrm{e}$ central do Brasil. Várias áreas cultivadas no oeste do Estado do Paraná apresentaram o problema. Casualmente esse transtorno foi identificado na região de atuação da Cooperativa Agroindustrial Consolata (Copacol). Na ocasião, estava sendo conduzido um ensaio com o propósito de avaliar as diferentes combinações de produtos usados no tratamento de sementes de soja, além de novas combinações possíveis, em que foram observados tratamentos que apresentaram redução do problema (Fávero, 2010). As combinações de tratamentos estudados por Fávero (2010), que continham Co, Mo e inoculação de sementes, apresentaram baixa frequência de plantas com distúrbios fisiológicos naquela safra.

Com o objetivo de comprovar as hipóteses das observações descritas no trabalho de Fávero (2010), buscou-se avaliar como a disponibilidade de $\mathrm{N}$ via inoculação e uso de Co e Mo no tratamento de sementes, associando fungicida e inseticida na soja, podem minimizar a retenção foliar e haste verde. 


\section{MATERIAL E MÉTODOS}

O experimento foi conduzido no município de Cafelândia, PR, localizado a $24^{\circ} 39^{\prime} 25^{\prime \prime}$ de latitude sul, $53^{\circ} 17^{\prime} 03$ 'de longitude oeste e $535 \mathrm{~m}$ de altitude, em relação ao nível do mar, em área experimental pertencente à Cooperativa Agroindustrial Consolata (Copacol), em solo de textura argilosa, classificado como Latossolo Vermelho distroférrico (Embrapa, 1999).

Por ocasião da implantação do ensaio, amostras foram coletadas na camada de $0-20 \mathrm{~cm}$ e caracterizadas quimicamente (Embrapa, 2009), sendo: $\mathrm{pH}\left(\mathrm{CaCl}_{2}\right)$ 4,7;

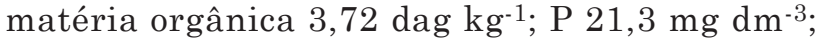
$\mathrm{K}^{+}$0,66 $\mathrm{cmol}_{\mathrm{c}} \mathrm{dm}^{-3} ; \mathrm{Ca}^{2+} 4,99 \mathrm{cmol}_{\mathrm{c}} \mathrm{cm}^{-3} ; \mathrm{Mg}^{2+} 1,56$ $\mathrm{cmol}_{\mathrm{c}} \mathrm{cm}^{-3} ; \mathrm{Al}^{3+} 0,14 \mathrm{cmol}_{\mathrm{c}} \mathrm{cm}^{-3} ; \mathrm{T} 14,69 \mathrm{cmol}_{\mathrm{c}} \mathrm{cm}^{-3}$; $\mathrm{V} \mathrm{49,1 \% ;} \mathrm{S} \mathrm{7,72} \mathrm{mg} \mathrm{dm}^{-3}$; Cu 24,15 mg dm ${ }^{-3}$; Zn 35,90 $\mathrm{mg} \mathrm{dm}{ }^{-3} ; \mathrm{Fe} 42,00 \mathrm{mg} \mathrm{dm}^{-3}$; Mn 223,00 $\mathrm{mg} \mathrm{dm}^{-3}$; e B $0,72 \mathrm{mg} \mathrm{dm}^{-3}$. As informações meteorológicas coletadas durante o período de desenvolvimento do ensaio encontram-se na figura 1.

Foram avaliados os efeitos do uso de inseticida/ fungicida, Co, Mo e inoculante (Bradyrhizobium japonicum), aplicados isoladamente e em combinação no tratamento de sementes do cultivar Don Mario 7.0 (BMX Magna RR), na safra 2010/2011 (Quadro 1). O volume de calda utilizado no tratamento de sementes foi igual para todos os tratamentos $(600 \mathrm{~mL}$ para $100 \mathrm{~kg}$ de semente).

O delineamento experimental adotado foi em blocos ao acaso, apresentando oito combinações de tratamentos e três repetições. As parcelas experimentais foram constituídas de sete linhas de $14 \mathrm{~m}$ de comprimento, espaçadas de 0,45 m entre si, perfazendo área total de $44,1 \mathrm{~m}^{2}$; a área útil de colheita foi constituída de quatro linhas de $6 \mathrm{~m}$ de comprimento, espaçadas de $0,45 \mathrm{~m}$ e perfazendo uma área de $10,8 \mathrm{~m}^{2}$.

Os tratamentos de semente com inseticida/ fungicida, Co e Mo foram realizados no dia 20 de outubro de 2010, tratando-se $5 \mathrm{~kg}$ de sementes para cada tratamento, sendo a inoculação de sementes realizada no momento da semeadura.
O experimento foi instalado no dia 21 de outubro de 2010, empregando-se a cultivar BMX Magna RR, produzida pela Copacol, em sistema de semeadura direta, realizada mecanicamente, distribuindo-se 14 sementes por metro linear e adubando-se com $6 \mathrm{~kg} \mathrm{ha}^{-1}$ de $\mathrm{N}, 72 \mathrm{~kg} \mathrm{ha}^{-1}$ de $\mathrm{P}_{2} \mathrm{O}_{5}$ e $48 \mathrm{~kg} \mathrm{ha}^{-1}$ de $\mathrm{K}_{2} \mathrm{O}$, na forma de $300 \mathrm{~kg} \mathrm{ha}^{-1}$ do formulado 02-24-16. $\mathrm{O}$ controle de plantas daninhas foi efetuado com duas aplicações de Glifosato nos estádios V3 e V6, e as lagartas foram controladas preventivamente com duas aplicações do inseticida seletivo Teflubenzuron, nos estádios V6 e R1. Os percevejos foram monitorados; ao atingir um nível de 0,5 percevejo por pano de batida, adotou-se o manejo químico para o controle, utilizando o inseticida Tiametoxan + Lambda-Cialotrina. O controle de doenças foi realizado com a aplicação de Piraclostrobina + Epoxiconazol, nos estádios R1, R3 e R5.

$\mathrm{O}$ teor de $\mathrm{N}$ foliar foi determinado, coletando-se a terceira folha com pecíolo do ápice para a base da planta, no estádio R1, em 10 plantas por parcela. As amostras foram acondicionadas em saco de papel e encaminhadas para análise conforme método descrito por Tedesco et al. (1995).

Por ocasião da colheita, realizada em 18 de março de 2011, foram determinados o percentual de plantas anormais, altura de plantas e componentes do rendimento. $\mathrm{O}$ percentual de plantas anormais foi definido pela contagem do número de plantas com presença de haste verde, em relação ao total de plantas em $5,4 \mathrm{~m}^{2}$ de parcela. A altura de plantas foi estipulada pela medição do comprimento entre o solo até vagem do ápice da planta, em cinco plantas ao acaso dentro da parcela. $\mathrm{O}$ número de vagens por planta e grãos por vagem foi estabelecido a partir da contagem de vagens com 0, 1, 2, 3 e 4 grãos, em plantas de soja coletadas em $2 \mathrm{~m}$ de comprimento da parcela. Essas contagens foram transformadas em porcentagem para definir a proporção das respectivas vagens, em relação ao total.

O rendimento de grãos foi calculado a partir do peso de grãos na colheita de $10,8 \mathrm{~m}^{2}$ de parcela,

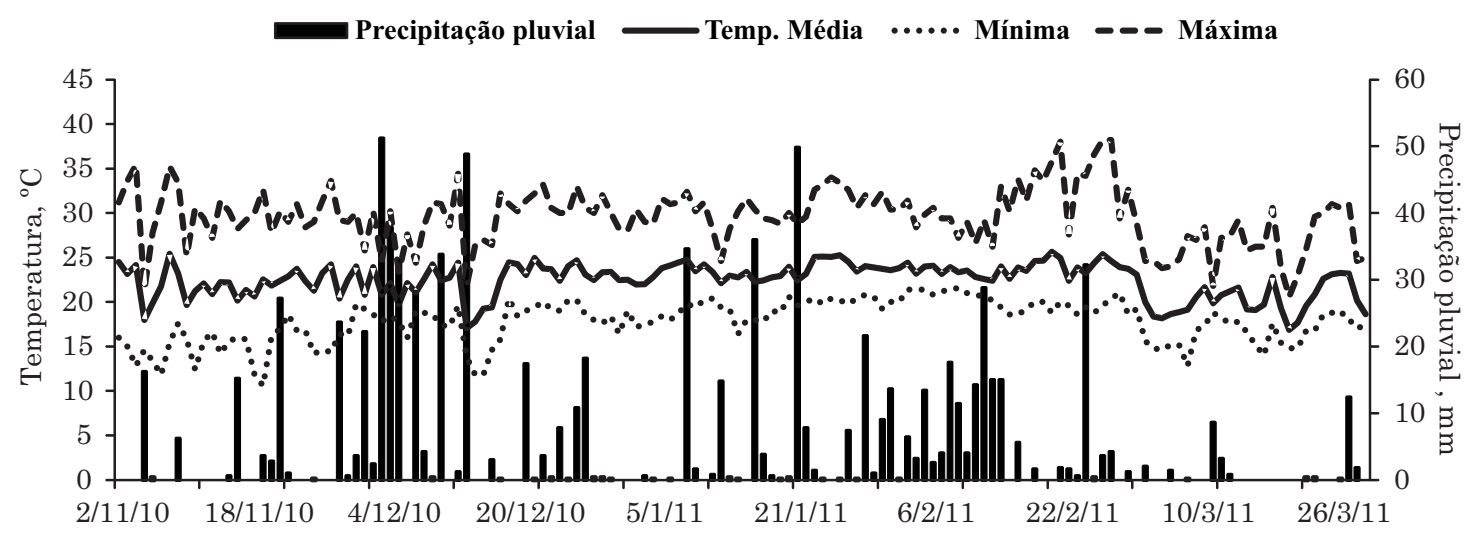

Figura 1. Precipitação pluvial, temperaturas máxima, mínima e média durante o período de desenvolvimento da cultura no ensaio. 
corrigido a uma umidade de $13 \%$, descontando-se as impurezas. A umidade dos grãos foi determinada por ocasião da colheita com equipamento Dickey-Jhon.

A massa de 1000 grãos foi calculada a partir da contagem e pesagem de 400 grãos por parcela e corrigida a umidade de $13 \%$. Em razão das plantas anormais, observou-se grande quantidade de impurezas por ocasião da colheita em algumas parcelas. Dessa forma, as vagens verdes e os pedaços de haste foram considerados como impurezas e obtidos a partir da limpeza e separação das sujidades na parcela colhida.

A análise dos resultados foi fundamentada no teste F, e as médias foram comparadas pelo teste de Tukey a $5 \%$.

\section{RESULTADOS E DISCUSSÃO}

As variáveis massa de 1000 grãos (MMG) e altura de plantas não apresentaram diferença significativa $(p<0,05)$ em razão da combinação dos tratamentos envolvendo inoculação, da adubação com Co e Mo e do uso do inseticida e do fungicida aplicados via tratamento de sementes (Quadro 2).

Durante a fase vegetativa da soja, observou-se clorose intensa nas parcelas onde não foram utilizados Co, Mo e, ou, inoculante (Figura 2), refletindo diretamente no teor de $\mathrm{N}$ foliar, avaliado no estádio R1 (Figura 3b). Os sintomas de clorose são típicos da deficiência de $\mathrm{N}$, que por sua vez pode estar correlacionada à deficiência da inoculação e, ou, dos micronuntrientes Mo e Co (Sfredo \& Borkert, 2004). Observa-se na figura 1 que durante o período vegetativo da cultura as precipitações foram intensas, levando a cultura a condições temporárias de hipoxia, que, associadas à ineficiência de nodulação, podem ter ocasionado a clorose foliar. Amarante et al. (2007), estudando a eficiência da estirpes de Bradyrhizobium em solo inundado, observaram redução significativa dos teores de clorofila foliar com a hipoxia pela ineficiência da fixação simbiótica nessas condições. Frequentemente, o teor foliar de clorofila está associado à concentração de N na planta (Yoder \& PettigrewCrosby, 1995), que pode ser influenciado por condições ambientais à restrição da fixação de $\mathrm{N}_{2}$ pela hipoxia.

A melhor nutrição da planta com $\mathrm{N}$ via inoculação de sementes ou ainda via utilização do Co e do Mo no tratamento de sementes promoveu aumento no rendimento de grãos (Figura 3a,b). A combinação do inoculante com o inseticida e o fungicida promoveu maior número de plantas anormais, quando comparada ao tratamento que incluía apenas o uso isolado do inoculante (Figura 4c). De acordo com Baudet \& Peske (2007), a prática de tratamento de sementes com inseticidas e fungicidas confere à planta condições de defesa, contribuindo para obtenção do stand inicial almejado na presença de pragas e doenças. Essa redução do rendimento de grãos quando comparada à ausência do produto pode ser atribuída à possível ação dos componentes da fórmula sobre a

Quadro 2. Altura de plantas e massa de 1000 grãos (MMG) da soja em razão de diferentes combinações de tratamento de sementes

\begin{tabular}{lcc}
\hline Tratamento & Altura de planta & MMG \\
\hline & $\mathrm{cm}$ & $\mathrm{g}$ \\
Controle & $114,0 \mathrm{a}$ & $123,0 \mathrm{a}$ \\
Co Mo & $110,0 \mathrm{a}$ & $131,0 \mathrm{a}$ \\
Inoculante & $115,0 \mathrm{a}$ & $126,0 \mathrm{a}$ \\
Inseticida/fungicida & $114,0 \mathrm{a}$ & $125,3 \mathrm{a}$ \\
Co Mo+inoculante & $121,6 \mathrm{a}$ & $126,3 \mathrm{a}$ \\
Inseticida/fungicida+Co Mo & $119,0 \mathrm{a}$ & $131,0 \mathrm{a}$ \\
Inseticida/fungicida+inoculante & $115,0 \mathrm{a}$ & $131,0 \mathrm{a}$ \\
Inseticida/fungicida+Co Mo+inoculante & $122,3 \mathrm{a}$ & $129,3 \mathrm{a}$ \\
Média & 116,5 & 127,9 \\
CV (\%) & 3,60 & 3,25 \\
\hline
\end{tabular}

Médias seguidas de mesma letra não diferem entre si pelo teste de Tukey $(p<0,05)$.

\section{Quadro 1. Combinação de tratamentos de semente utilizados na condução do ensaio}

\begin{tabular}{|c|c|c|}
\hline Tratamento & Produto comercial & Dose \\
\hline & & $\mathrm{L} \mathrm{ha}^{-1}$ \\
\hline \multicolumn{3}{|l|}{ Controle } \\
\hline Co Mo & CoMo Platinum ${ }^{\circledR}$ & 0,15 \\
\hline Inoculante & Cell Tech ${ }^{\circledR}$ & 0,10 \\
\hline Inseticida/fungicida & Standak Top ${ }^{\circledR}$ & 0,125 \\
\hline Co Mo + inoculante & CoMo Platinum ${ }^{\circledR}+$ Cell Tech $^{\circledR}$ & $0,15+0,10$ \\
\hline Inseticida/fungicida + Co Mo & Standak Top ${ }^{\circledR}+$ CoMo Platinum ${ }^{\circledR}$ & $0,125+0,15$ \\
\hline Inseticida/fungicida + inoculante & Standak Top ${ }^{\circledR}+$ Cell Tech ${ }^{\circledR}$ & $0,125+0,10$ \\
\hline Inseticida/fungicida + Co Mo + inoculante & Standak Top $^{\circledR}+$ CoMoPlatinum $^{\circledR}+$ Cell Tech ${ }^{\circledR}$ & $0,125+0,15+0,10$ \\
\hline
\end{tabular}

Standak Top 500 FS $^{\circledR}$ (250 g de fipronil $+25 \mathrm{~g}$ de piraclostrobina $+225 \mathrm{~g}$ de tiofanato metílico); CoMo Platinum ${ }^{\circledR}(15 \%$ de molibdênio $+1,5 \%$ de cobalto); Cell Tech ${ }^{\circledR}$ (Bradyrhizobium japonicum - estirpes SEMIA 5080 e SEMIA 507 na concentração 1,5 $\times 10^{9}$ células viáveis $/ \mathrm{mL}$ ). 

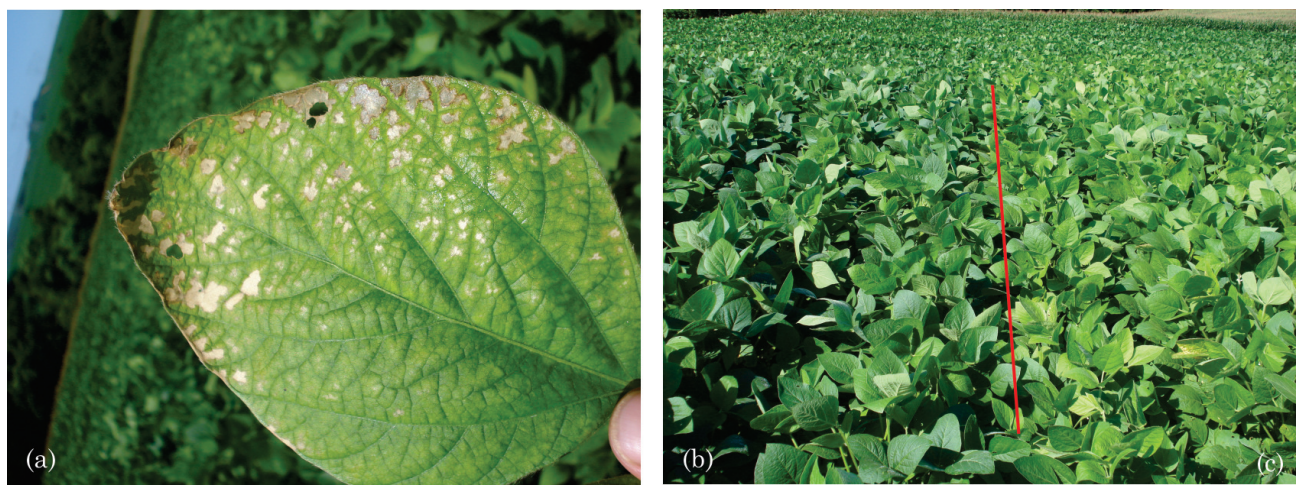

Figura 2. Clorose foliar na fase vegetativa da soja, sem a adição de Co, Mo e, ou, inoculante no tratamento de sementes (a) e comparação entre os tratamentos com inoculante e controle, T4 e T1, respectivamente (b, c). Safra 2010/11.
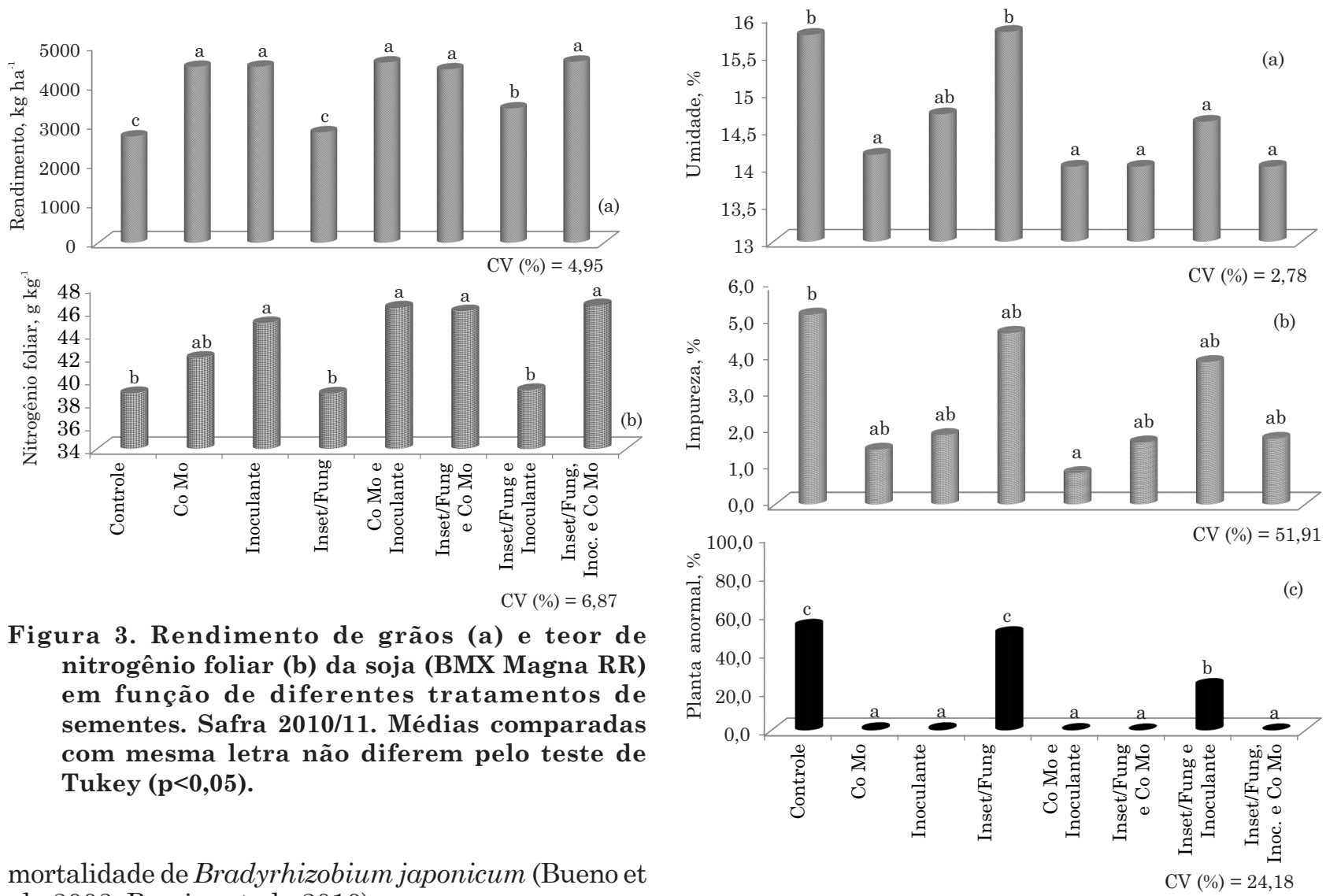

mortalidade de Bradyrhizobium japonicum (Bueno et al., 2003; Pereira et al., 2010).

O Mo é um componente essencial na atividade das duas principais enzimas no processo de assimilação de $\mathrm{N}$ (nitrogenase e redutase do nitrato), influindo decisivamente no metabolismo do $\mathrm{N}$ na planta (Floss, 2004). A resposta observada para o Co e o Mo neste trabalho pode estar relacionada ao baixo valor de $\mathrm{pH}$ do solo $(4,7)$, onde foi instalado o ensaio. Lantmann et al. (1989) observaram que a resposta da soja à adição de Mo esteve intimamente relacionada com o $\mathrm{pH}$ do solo, sendo as maiores respostas obtidas em solos com baixos valores de $\mathrm{pH}$ em $\mathrm{CaCl}_{2}(<4,3$ em LRa e $<4,8$ em LEa). A calagem tem sido considerada prática eficiente em influenciar o adequado suprimento de Mo,

Figura 4. Umidade dos grãos na colheita (a), impurezas na colheita (b) e percentual de plantas anormais (c) em função de diferentes tratamentos de sementes. Safra 2010/11. Médias seguidas de mesma letra não diferem pelo teste de Tukey $(p<0,05)$.

por torná-lo mais disponível às plantas (Rosolem \& Caires, 1998), em consequência da elevação do $\mathrm{pH}$ do solo, que promove liberação de íons de Mo adsorvidos na superfície dos óxidos de $\mathrm{Fe}$ e $\mathrm{Al}$.

A deficiência de Co pode também ter inibido a formação da leg-hemoglobina no nódulo, reduzindo a fixação biológica do $\mathrm{N}$ atmosférico, como descrito por 
Floss (2004). Assim, houve aumento na fixação de N nas plantas, que foram tratadas com Co e, consequentemente, no rendimento de grãos.

Observou-se que o número de plantas anormais na parcela interferiu na qualidade física (impureza e umidade) da colheita (Figura 4a,b,c). A haste verde ocasionou problemas de colheita, aumentando o teor

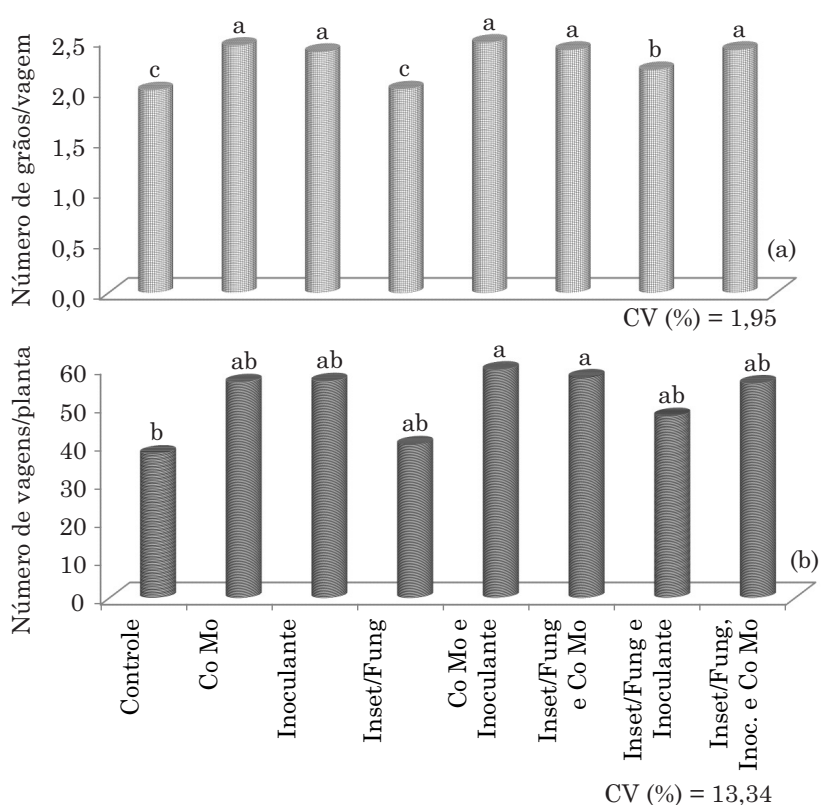

Figura 5. Número de grãos por vagem (a) e número de vagens por planta (b), em função de diferentes tratamentos de sementes. Safra 2010/ 11. Médias seguidas de mesma letra não diferem pelo teste de Tukey $(p<0,05)$. de umidade e as impurezas (Figura 4a,b) e contribuindo para redução do rendimento de grãos. Fávero (2010) observou que, no ensaio conduzido na safra 2009/10, a porcentagem de plantas anormais estava diretamente relacionada ao rendimento de grãos das parcelas colhidas, sendo o fator determinante para o rendimento naquele ensaio. Além da redução do rendimento, a presença de haste verde e retenção foliar causa aumento dos custos de produção, em razão da necessidade de utilizar produtos para dessecação da cultura, a fim de se efetuar a colheita mecanizada.

$\mathrm{Na}$ figura 5, estão representados os dados do número de vagens por planta e o número de grãos por vagem em razão das combinações dos tratamentos estudados; houve relação direta entre a frequência de plantas anormais da parcela (Figura 4c) com a quantidade de grãos e vagens formadas (Figura 5a,b). Fávero (2010) descreveu que as plantas anormais apresentam menor número de vagens por planta e grãos por vagens em relação as plantas normais, atribuindo a causa da retenção foliar à deficiência de dreno para os fotoassimilados produzidos na folha. Os tratamentos que receberam inoculação e, ou, Co e Mo no tratamento de sementes apresentaram os maiores valores para o número de grãos por vagens e vagens por planta, contribuindo significativamente como componentes importantes do rendimento.

Quanto aos percentual de vagens com diferentes números de grãos formados em razão dos tratamentos estudados, observou-se que quando não se utilizou Co e Mo e, ou, inoculante houve aumento na proporção de vagens partenocárpicas, com apenas um grão formado ( $25 \%$ do total de vagens) e redução no número de vagens com três grãos formados (Figura 6). Os

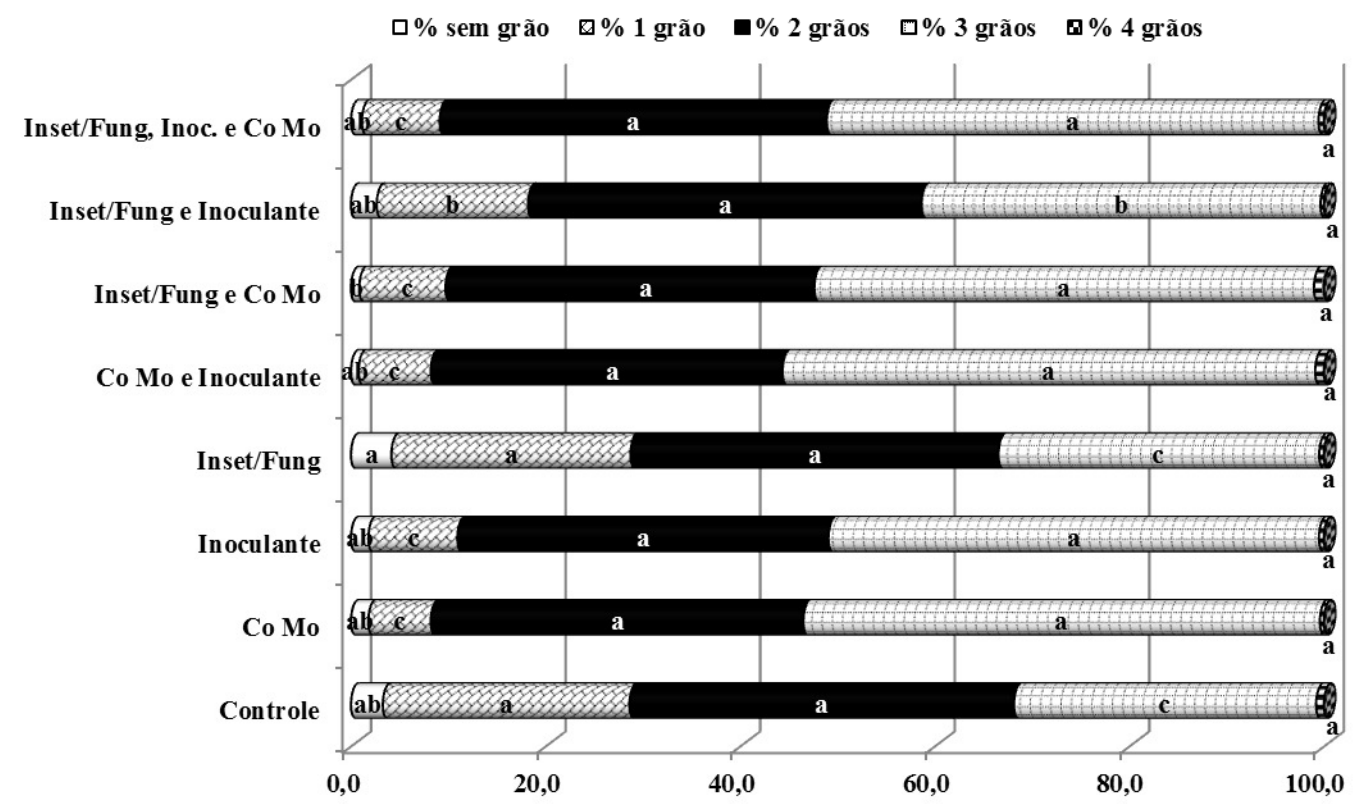

Figura 6. Percentual de vagens de soja com zero, um, dois, três e quatro grãos formados em função de diferente combinação de tratamentos de sementes. Safra 2010/11. Médias seguidas de mesma letra entre barras não diferem pelo teste de Tukey $(p<0,05)$. 
tratamentos com inseticida/fungicida isolado ou em mistura com inoculante aumentaram a porcentagem do número de vagens com apenas um grão formado. Campos \& Hungria (2000) destacaram que o uso de fungicidas no tratamento de sementes pode reduzir a fixação biológica por $B$. japonicum em razão da taxa de mortalidade de bactérias ocasionada pelo fungicida. Porém, quando o inseticida/fungicida foi adicionado em mistura com o Co e Mo não houve esse efeito, tendo o tratamento com esses elementos proporcionado melhor disponibilização de $\mathrm{N}$ pelas bactérias presentes no solo e, ou, inoculadas.

Os resultados evidenciaram que ocorrem mudanças fisiológicas da planta de soja quando não há nutrição equilibrada em $\mathrm{N}$, reduzindo o número de vagens por planta (Figura 5) e aumentando a porcentagem de vagens com apenas um grão formado (Figura 6). A redução do dreno na planta promovida pelo menor número de grãos ocasionou o aumento do número de plantas anormais, fenômeno também chamado de haste verde.

\section{CONCLUSÕES}

1. A redução da disponibilidade de $\mathrm{N}$ ocasiona clorose foliar, aumenta a proporção de vagens com apenas um grão formado, reduz o número de vagens por planta e grãos por vagem, promovendo maior frequência de plantas anormais.

2. O uso do Co e Mo e a inoculação de sementes promovem aumento do teor de $\mathrm{N}$ foliar na soja e reduzem o número de plantas anormais, refletindo positivamente no rendimento de grãos e seus componentes.

3. Este trabalho afirma a necessidade da utilização do Co e Mo no tratamento de sementes e da inoculação de sementes com Bradyrhizobium japonicum, visando à redução do problema de haste verde.

\section{LITERATURA CITADA}

AMARANTE, L.; COLARES, D.S.; OLIVEIRA, I.L.; BADINELLI, P.G. \& BERNARDI, E. Teores de clorofilas em soja associada simbioticamente com diferentes estirpes de Bradyrhizobium sob alagamento. R. Bras. Bioci., 5:906908, 2007.

BAUDET, L. \& PESKE, F. Aumentando o desempenho das sementes. Seed News, 9:22-24, 2007.

BUENO, C.J.; MEYER, M.C. \& SOUZA, N.L. Efeito de fungicidas na sobrevivência de Bradyrhizobium japonicum (Semia 5019 e Semia 5079) e na nodulação da soja. Acta Sci. Agron., 25:231-235, 2003.

CAMPOS, J. R. \& HUNGRIA, M. Compatibilidade de uso de inoculantes e fungicidas no tratamento de sementes de soja. Londrina, Embrapa Soja, 2000. 32p. (Circular Técnica, 26)
EMPRESA BRASILEIRA DE PESQUISA AGROPECUÁRIA EMBRAPA. Complexidade da Soja Louca II exige intensificação das pesquisas. Disponível em: <http:// $\mathrm{w} w \mathrm{w}$. c n p s o.e m b r p a. b r / n o t i c i a / ver_noticia.php?cod_noticia $=650>$. Acesso em: 20 jun. 2011.

EMPRESA BRASILEIRA DE PESQUISA AGROPECUÁRIA EMBRAPA. Sistema brasileiro de classificação de solos. Rio de Janeiro - CNPS, 1999. 412p.

EMPRESA BRASILEIRA DE PESQUISA AGROPECUÁRIA EMBRAPA. Tecnologias de Produção de Soja - Região Central do Brasil 2009 e 2010. Londrina, 2008. 261p. (Sistemas de Produção, 13)

EMPRESA BRASILEIRA DE PESQUISA AGROPECUÁRIA EMBRAPA. Manual de análises químicas de solos, plantas e fertilizantes. 2.ed. Brasília, 2009. 627p.

FÁVERO, F. Ocorrência de Soja Louca II no Estado do Paraná. R. Plantio Direto, 118: 15-17, 2010.

FLOSS, E. L. Fisiologia das plantas cultivadas: o estudo que está por trás do que se vê. 2. ed. Passo Fundo, Universidade de Passo Fundo, 2004. p.214-231.

LANTMANN, A.F.; SFREDO, G.J.; BORKERT, C.M. \& OLIVEIRA, M.C.N. Resposta da soja a molibdênio em diferentes níveis de $\mathrm{pH}$ do solo. R. Bras. Ci. Solo, 13:4549, 1989.

MASCARENHAS, H.A.A.; TANAKA, R.T.; WUTKE, E.B.; BULISANI, E.A.; BRAGA, N.R. \& MIRANDA, M.A.C. Potássio para a soja. O Agronômico, 55:20-21, 2003.

PEREIRA, C.E.; OLIVEIRA, J.A.; CALDEIRA, C.M. \& BOTELHO, F.J.E. Efeito do tratamento das sementes de soja com fungicidas e período de armazenamento na resposta da planta inoculada com Bradyrhizobium. R. Agro@mbiente On-line, 4:62-66, 2010.

ROSOLEM, C.A. \& CAIRES, E.F. Yield and nitrogen uptake of peanuts as affected by lime, cobalt and molybdenum. J. Plant Nutr., 21:827-835, 1998 .

SÁ, D. Soja louca II pode gerar prejuízos de até $40 \%$ na produtividade das plantações. Disponível em: <http:// revistagloborural.globo.com/Revista/Common> Acesso em: 20 mar. 2012

SFREDO, G.J. \& BORKERT, C.M. Deficiência e toxicidades de nutrientes em plantas de soja: Descrição dos sintomas e ilustração com fotos. Londrina, Embrapa, 2004. 44p. (Documentos, 231)

SOSA-GOMEZ, D.R. \& MOSCARDI, F. Retenção foliar diferencial em soja provoca por percevejos (Heteroptera: pentatomidae). Anais Soc. Entomol. Brasil, 24:401-404, 1995.

TEDESCO, M.J.; GIANELLO, C.; BISSANI, C.A.; BOHNEM, H. \& VOLKWEISS, S.J. Análises de solo, plantas e outros materiais. 2.ed. Porto Alegre, UFRGS, 1995. 174p.

YODER, B.J. \& PETTIGREW-CROSBY, B.E. Predicting nitrogen and chlorophyll content and concentrations from reflectance spectra (400-2500 $\mathrm{nm})$ at leaf and canopy scales. Remote Sens. Environ., 53:199-211, 1995. 